\title{
Editorial \\ The Peer-review Process: The Good, the Bad, the Ugly, and the Extraordinary
}

\author{
Arie Y. Lewin \\ Duke University, USA
}

This issue of MOR features three perspectives on reviewing that were commissioned by Professor Anne Tsui, the emeritus founding Editor-in-Chief of MOR. The title of this editorial reflects my long career as Editor (starting as Departmental Editor in Management Science, Founding Editor-in-Chief of Organization Science, Editor-in-Chief of Journal of International Business Studies and currently of MOR). This editorial briefly considers the purpose of the peer-review process and the reality of peer-reviewed publications. Looking forward, I also outline aspirations for the peer-review process for $M O R$ and how that process fits with $M O R$ 's redesigned submission policies.

\section{THE PEER-REVIEW PROGESS}

A review of any social science journal reveals that journals seek to publish path-breaking, original research, involving major (nontrivial) research questions. Research that tests theoretically grounded hypotheses utilizing suitable data and context, that engages appropriate state-of-the art empirical methods, and that reports interesting findings with useful implications. The peer-review process is intended both to ascertain that the research represents an original contribution to knowledge and that it meets criteria of originality, rigor, and relevance (Daft \& Lewin, 2008).

In reality, however, journals in the social sciences, regardless of their impact factor, publish midrange or minor theorizing and incremental empirical results, and in general explain a small fraction of variance. Overall, the average unexplained variance for a random sample of major journals deploying statistical regression 


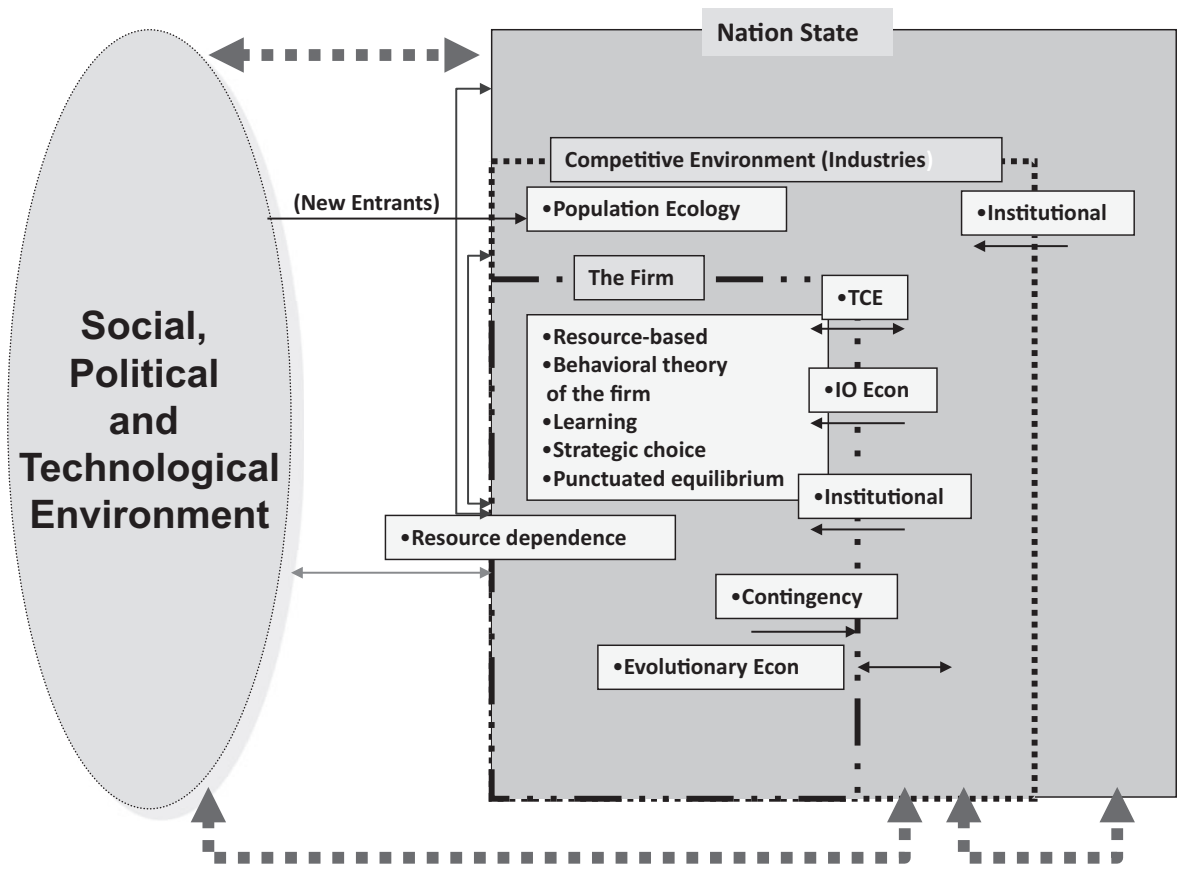

(c) Arie Y. Lewin

Lewin et. al 2004

Figure 1. Many competing theories in management research: Low explained variance?

studies exceeds 78\% (Chen \& Lewin, 2013). One reason empirical studies explain such a low proportion of the variance stems from the many competing, midrange theories of the same and/or overlapping phenomena. Figure 1 serves to illustrate the wide range of theories and frameworks that are integral elements of the social sciences underlying management research (Lewin, Weigelt, \& Emery, 2004). The theories and models positioned in Figure 1 are examples of theories that focus on phenomena within the organization black box and between the organization and its competitive and institutional environment, and on the role of disruptions due to social and political movements as well as technological advances.

Although most of the time the peer-review process serves to ensure the publication of original research, it is important to recognize that the definition of original research is determined by the configuration of theories that authors select for framing the research and by the willingness of the peer reviewers to apply the same configuration of theories in evaluating the research. Not surprisingly, the reviewer's view of the appropriateness and originality of the research depends on whether the authors and reviewers overlap in terms of their theoretical and methodological preferences.

The rigor of the peer review process is also no guarantee that the paper will have an impact as measured by citations (excluding self-cites). The reality is that most 
peer-reviewed papers are never cited and that less than $15 \%$ of scholars account for more than $75 \%$ of all citations. In the social sciences (as opposed to the physical sciences, such as physics and chemistry) it takes four to eight years before the citations to an article point to a potential 'block buster article' (Daft \& Lewin, 2008). On average 30.5 years pass before a paper published in the premier social science field of economics is recognized as a Nobel Prize paper. Not surprisingly, 'blockbuster' papers also appear in lower-impact-factor journals (see extensive analysis by Starbuck, 2005).

The inescapable conclusion is that authors, editors, and reviewers are poor judges of predicting high-impact papers at the time the paper is accepted for publication in a peer-reviewed social science journal. Nevertheless, advances in the social sciences have occurred within the framework of peer-reviewed journals. The emergence of new social science paradigms that cannot find acceptance within the established societies and journals of the time often results in the formation of a new social science community and a new peer-reviewed journal (e.g., the Academy of International Business and its Fournal of International Business Studies in 1968; and the International Association for Chinese Management research and its journal Management and Organization Review in 2005). However, in many other cases existing societies launch interest groups and additional journals to serve the new interest groups within their societies (e.g., Strategic Management Society launched Global Strategy Fournal and Entrepreneurship Strategy fournal and INFORMS launched Organizations Science, and most recently Strategy Science). In the long run, such dynamic adaptations create the basis for the ongoing evolution and recreation of the social science.

\section{REST OF WORLD ADOPTS US-GENTRIG SGHOLARSHIP METRIC}

In recent years, a new dynamic is affecting publications in peer-reviewed journals, especially the high-impact-factor journals. The phenomenon involves governments in countries outside of the USA engaging in a process of quantifying the scholarship of scientists in their countries as a way of rationalizing the allocation of national resources to institutions of higher learning in their countries. It is beyond the scope of this editorial to discuss and comment on this development (see also final editorial by Tsui, 2013), except to note that knowledge creation by scholars in the social and physical sciences is increasingly being evaluated in terms of its publication in the highest rated impact-factor peer-reviewed journals (designated the $\mathrm{A}, \mathrm{A}^{-}$and $\mathrm{B}$ peer-reviewed journals). The unsurprising consequence has been a dramatic increase in submissions to the top journals by scholars from emerging economies as well as from European countries, and a decrease in the variety and type of published scholarship involving books, qualitative in-depth case studies, contributions to edited volumes, etc. 
The significant increase in submissions to high-impact-factor, peer-reviewed journals has had several consequences. Among them, a high increase in 'desk reject' decisions (some journals have reported a tripling in the desk reject rates), and a decrease in the quality and developmental aspects of the peer-review process often attributed to an overworked editorial review structure and difficulties encountered in recruiting qualified and dedicated reviewers.

Another development involves national initiatives involving significant investments in upgrading the scholarship potential of their existing stock of science, technology, engineering, and mathematics scholars and researchers (e.g., China 985 initiative; Zhang, Patton, \& Kenney, 2013); and a concerted effort at subsidizing the full cost of educating students who have been admitted for studies toward advanced degrees in universities in more advanced countries (e.g., in Kazakhstan, students who are selected on the basis of stringent merit criteria are awarded prestigious Bolashak fellowships to study at approved top universities worldwide). Such initiatives serve to enrich international research exchanges as well as to increase the number of scholars competing to publish in the top impact factor journals. In some emerging economies, the top universities restrict recruiting of new faculty to nationals who have earned advanced degrees from the best universities in the USA and other developed economies. Moreover, the employment contract often specifies that promotion and tenure require that the new faculty member publish a specific number of papers per year in an $\mathrm{A}, \mathrm{A}^{-}$or $\mathrm{B}$ impact-factor journal.

One other consequence of the pressure to publish in high-impact-factor, peer-reviewed journals is a reported increase in cheating and self-plagiarism. Cheating includes studies based on 'made up' data; outright plagiarism without proper citations; and self-plagiarism of prior published research by the same author (Tsui, 2013). In response, all peer-reviewed journals that I am familiar with, including $M O R$, as well as most reputable commercial journal publishers, now use various services that screen submitted manuscripts for possible violations of the rule that authors must submit original research. Moreover, all journals require that authors submit a statement certifying that the manuscript represents original work and that it is not simultaneously under review by another peerreviewed journal. I have no personal knowledge of how severe or prevalent academic cheating is, but it is plausible that the pressure to publish in a relatively small number of high-impact-factor, peer-reviewed journals has contributed to this cheating phenomenon.

The discussion so far has reprised the origin, importance, and self-regulating processes of the peer-review process and highlighted the recent bad and ugly aspects of this process. To some degree the pressure toward instrumentalism is a direct consequence of what March (2005) referred to as the process of creeping parochialism. But much of it may represent a direct consequence of the new external environmental dynamics. 


\section{THE EXTRAORDINARY ASPIRATIONS FOR THE MOR PEER-REVIEW PROGESS}

The challenge for $M O R$ going forward is to organize its editorial policies, structure, and peer-review processes to maximize its openness to publishing scholarship that challenges established theories, opens new research directions, and shuts down over-explored areas. The domain of $M O R$ is scholarship published in social science journals underlying management and strategy research in the context of China and all other emergent economies. In the section that follows I wish to describe the new MOR peer-review process and the aspiration and commitment first to identify the potential 'jewel' in a paper and then guide author(s) to successful publication.

To open $M O R$ to publishing scholarship that challenges established theories, opens new research directions, and shuts down over-explored areas, as well as to greatly increase the variety of scholarship, theories, and empirical methods accepted for publication in $M O R$, the editorial structure has been decentralized and editorial power has devolved to independent autonomous Senior Editors. The new Senior Editor team enables broad and diverse coverage of micro- and macro-research themes, as well as diverse theoretical roots, research phenomena, and empirical methodologies. The team members' editorial decisions are binding on the journal. To maximize their attention to each manuscript, the work load of Senior Editors is limited to ten manuscripts per calendar year. Building the new MOR Editorial Review Board involved each Senior Editor recruiting at least six members of the Editorial Review Board, whose first responsibility is to review papers for their Senior Editor. All Senior Editors and Editorial Review Board members are committed to the new MOR review process.

This process begins with the new submission policy. When authors submit a paper for consideration by $M O R$, they are asked to nominate two Senior Editors who they believe best match the domain of their paper. In addition, authors are asked to nominate up to four ad hoc reviewers, whose scholarship overlaps or is related to the domain of their paper. The nominated ad hoc reviewers must have a strictly arms length relationship with authors. This very important step is intended to establish a better match between the subject matter of the paper under review and the subject matter experts who will be invited to review the paper. Early experience (since September 2013) indicates that authors who have followed this submission process benefit from a markedly deeper developmental review process. The ad hoc reviewers (nominated by the author) often provide insights that are extremely valuable in informing and shaping the Senior Editor's editorial decision.

The format of MOR editorial letters has also been revised. The opening paragraph is expected to convey to the author(s) a summary of the research question or phenomena that the paper is addressing and to indicate the reviewers' degree of enthusiasm for this research question. The remainder of the review process follows the established $M O R$ developmental review process, with a few exceptions. 
The most important is to refrain from offering a line-by-line review and directions tantamount to forcing the author to rewrite the paper that the reviewer wishes he or she had written. In addition, MOR editorial review letters will not classify Revise and Rewrite invitations as high-risk or give any indication of how risky the revision process may be. I strongly believe that if the peer reviews and editorial letters are comprehensive and developmental and outline a road map for what needs to be done during the revision stage, the author can judge for herself or himself how risky the revision and rewriting task may be.

Of course, MOR papers must meet or exceed the relevant bar of other top journals, whether it involves theory development, literature review, or empirical methods. If the paper utilizes a new empirical method such as fuzzy Qualitative Comparative Analysis (Judge, Fainshmidt, \& Brown, 2014) it must be executed at the current state-of-the-art standards. There can be no doubt about commitment to academic rigor of papers published in MOR. However, since no empirical paper is perfect and since the explained variance can be expected to be quite low, $M O R$ requires papers published in $M O R$ to include a substantive discussion of alternative or competing theoretical explanation for the reported findings as well a discussion of potential theoretical explanations for sources of variation making up the unexplained variance. Although many journals also claim that papers should also be relevant to practitioners and policy-makers, moving forward MOR will not require such explorations or discussions as condition for publication. Authors are welcome and encouraged to engage issues of relevance. However, such discussion is entirely optional. The primary rational is discussed in Daft and Lewin (2008). It is anchored in the observation that as academic scholars we are at a disadvantage when it comes to understanding the selection process by which our research is considered to be relevant to practice.

As the three following essays describe, the peer-review process inherently involves an asymmetric power relationship between authors and reviewers. This is of course a reality shared by all peer-reviewed journals. However, MOR encourages and is open to authors cogently expressing and defending a disagreement that he or she may have with a direction from a specific reviewer or from the Senior Editor. This is an aspirational goal that has been explicitly and openly discussed at meetings of Senior Editors. MOR editors recognize that the peerreview process can be subjective and that honest misunderstandings can arise between reviewers and authors. Such occasions call for what Liu (2014) describes and advocates as a collaborative revise and rewrite process between author(s), reviewers, and editors to reach a mutually agreeable integrative outcome. This requires that authors should be given more voice in shaping the revisions that they would like to make. Tsang (2014) reinforces this aspiration by framing the role of the editor as mediating the revise and rewrite is process of 'give and take' between authors and reviewers and finding an equilibrium between ensuring manuscript quality and preserving the intent of the author. Hempel (2014) addresses the role 
of reviewers in the developmental process of preserving the voice of the author and achieving integrative outcomes. Hempel argues that the review process can be intrinsically satisfying when it is also framed as an opportunity for learning and personal growth and thereby counteract the mind set of reviewing as a burdensome obligation. MOR authors are encouraged to participate and shape the revise and rewrite process. I fully realize the reluctance that authors feel in testing this process. However, this is a change to which the editorial team of $M O R$ is committed to, and it is a strategic differentiator for delivering an extraordinary developmental peer review process.

\section{REFERENGES}

Daft, R. L., \& Lewin, A. Y. 2008. Rigor and relevance in organization studies: Idea migration and academic journal evolution. Organization Science Perspectives, 19(1): 177-183.

Hempel, P. S. 2014. The developmental reviewer. Management and Organization Revieze, 10(2): 175-181.

Judge, W. Q., Fainshmidt, S., \& Brown, J. L. 2014. Which model of capitalism best delivers both wealth and equality? Journal of International Business Studies, 45(4): 363-386.

Lewin, A. Y., Weigelt, C. B., \& Emery, J. B. 2004. Adaptation and selection in strategy and change: Perspectives on strategic change in organizations. In M. S. Poole \& A. H. Van de Ven (Eds.), Handbook of organizational change and innovation: 108-160. Oxford: Oxford University Press.

Liu, L. A. 2014. Addressing reviewer comments as an integrative negotiation. Management and Organization Revieze, 10(2): 183-190.

March, J. G. 2005. Parochialism in the evolution of a research community: The case of organization studies. Management and Organization Revieze, 1(1): 5-22.

Starbuck, W. H. 2005. How much better are the most-prestigious journals? The statistics of academic publication. Organization Science, 16(2): 180-200.

Tsang, E. W. K. 2014. Ensuring manuscript quality and preserving authorial voice: A balancing act of edits. Management and Organization Revieze, 10(2): 191-197.

Tsui, A. S. 2013. The spirit of science and socially responsible scholarship. Management and Organization Revieze, 9(3): 375-394.

Zhang, H., Patton, D., \& Kenney, M. 2013. Building global-class universities: Assessing the impact of the 985 Project. Research Policy, 42(3): 765-775. 